\title{
Hypertrophic cardiomyopathy: an important cause of sudden death
}

\author{
W J MCKENNA AND J E DEANFIELD \\ Division of Cardiovascular Disease, Royal Postgraduate Medical School, London
}

SUMMARY Retrospective analysis was performed to assess the natural history in relation to clinical and haemodynamic features in 37 patients in whom hypertrophic cardiomyopathy had been diagnosed in childhood. At diagnosis they were aged 1 to 14 years (mean 9 years). Eighteen presented with chest pain and either dyspnoea or symptoms of impaired consciousness or both; 19 were asymptomatic and were referred for evaluation of abnormalities detected during physical examination. During a mean follow up of nine years, 18 patients died, a cumulative annual medical mortality of $4 \cdot 8 \%$. Five patients experienced severe dyspnoea or chest pain: two of these had progressive dyspnoea and died in cardiac failure, and three died after myectomy. The 19 survivors were compared with the 11 sudden deaths. Eleven of the survivors and five of the sudden deaths were asymptomatic. Of 18 clinical, electrocardiographic, and haemodynamic features only syncope and electrocardiographic evidence of right ventricular hypertrophy were associated with sudden death. In children with hypertrophic cardiomyopathy sudden death was common and was not well predicted by clinical, electrocardiographic, or haemodynamic findings. Hypertrophic cardiomyopathy indicates a poor prognosis even if symptoms are absent or mild.

Hypertrophic cardiomyopathy is a familial heart muscle disorder which may become clinically manifest at any age..$^{1-4}$ In adults the natural history is characterised by the slow progression of symptoms and by the occurrence of sudden death. ${ }^{5} 6$ When the diagnosis of hypertrophic cardiomyopathy is made in childhood, those patients who present with or who subsequently develop cardiac failure have a poor prognosis as do affected relatives of probands who have died suddenly..$^{5-7}$ Most children, however, in whom hypertrophic cardiomyopathy is recognised, present with minor or paroxysmal symptoms or are detected because of abnormalities found on routine medical examination. ${ }^{5}$ Their prognosis is uncertain. The purpose of this study was to determine the natural history of these patients in relation to clinical and haemodynamic features.

\section{Study patients}

Between 1962 and 1980 the diagnosis of hypertrophic cardiomyopathy was made in 54 children aged less than 14 years who were subsequently followed up at the Hammersmith Hospital. In 17 the diagnosis was made during family screening of probands with hypertrophic cardiomyopathy. These patients, however, were excluded from the study because they were usually assessed after the sudden death of a sibling or parent. Patients with a bad family history are recognised to be at particular risk of dying suddenly and have previously been well characterised. $^{5-7}$ Eighteen of the remaining 37 patients presented with symptoms of chest pain, dyspnoea, or impaired consciousness: 19 were asymptomatic and were referred because of abnormalities detected during routine examination. Retrospective analysis was performed on these 37 children to assess their natural history and the prognostic value of clinical, electrocardiographic, and haemodynamic features at the time of diagnosis and at last follow up.

The children were aged 1 to 14 years (mean 9 years) at diagnosis. Twenty two were boys and 15 girls. The follow up was 1 to 21 years (mean 9 years) and all survivors have been seen at follow up examination since July 1982 . Twenty three patients were treated with propranolol 20 to $240 \mathrm{mg}$ daily (median $80 \mathrm{mg}$ ), 11 received no treatment and three had either digoxin or diuretics, or both. The diagnosis of hypertrophic cardiomyopathy was based on the typical clinical, haemodynamic, and angiographic features. ${ }^{8}$ In 33 patients the diagnosis was estab- 
lished by left and right ventricular haemodynamic and angiographic studies. Of the four patients in whom the diagnosis was made without invasive studies, two had clinical or echocardiographic features consistent with hypertrophic cardiomyopathy and were first degree relatives of propositi, and two had the typical clinical and $M$ mode echocardiographic features of hypertrophic cardiomyopathy and a left ventricular gradient. ${ }^{9}$ Patients were considered to have a left ventricular gradient if the pressure difference between the body of the left ventricle and the aorta was greater than $20 \mathrm{~mm} \mathrm{Hg}$ under basal conditions or during provocation (at first with isoprenaline infusion, later with the Valsalva manoeuvre or amyl nitrate). During catheterisation and angiography additional cardiac abnormalities were detected in five patients-one had a small ventricular septal defect, two had moderate to severe mitral regurgitation, and two had mild aortic incompetence.

The electrocardiograms recorded at the time of diagnosis and at last follow up were evaluated for rhythm disturbances, particularly atrial fibrillation; conduction disease including the PR interval, the QT interval corrected for heart rate $(Q T c=Q T \sqrt{R-R}$ interval), left axis deviation (mean frontal plane QRS axis $-30^{\circ}$ to $-150^{\circ}$ ) and bundle branch block; left and right atrial enlargement; and voltage criteria of left and right ventricular hypertrophy. ${ }^{10} 11$

\section{Analysis of data}

The survivors were compared with those patients who died suddenly and those who died in cardiac failure or after myotomy or myectomy. The $\chi^{2}$ test or, when appropriate, Fisher's exact test were used for qualitative comparison of clinical, electrocardiographic, and haemodynamic features of the survivors and the dead. Cumulative survival rates were derived from life table calculations. ${ }^{12}$

\section{Results}

The 37 patients were followed for a mean of 9 years, during which 18 patients $(49 \%)$ died: $11(30 \%)$ suddenly, two (five per cent) from cardiac failure, three (eight per cent) perioperatively after myotomy or myectomy, one from endocarditis (three per cent), and one from suicide (Figure). Eleven were boys and seven girls. Their age at death was 6 to 23 years (mean 14 years) and their survival was 2 to 13 years (mean 6 years) from the onset of symptoms and 1 to 12 years (mean 6 years) from diagnosis. The age at diagnosis of those who died and survived was identical (1 to 14 years, mean 9 years), however, follow up in the survivors was significantly longer

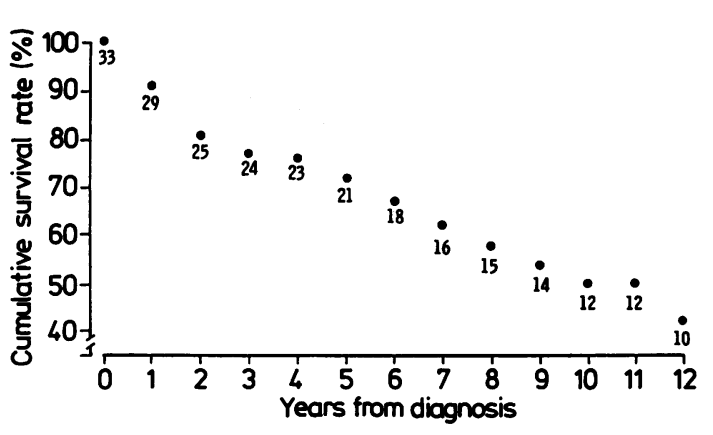

Figure Cumulative survival curve from the year of diagnosis for 33 medically treated patients.

The probability of death=the total number of deaths for the year divided by the adjusted number at risk minus the number of deaths due to other causes. The annual mortality in medically treated patients was $4 \cdot 8 \%$.

from the onset of symptoms ( 1 to 21 years, mean 13 years; $\mathrm{P}<0.01)$ and from diagnosis $(1$ to 21 years, mean 12 years; $P<0 \cdot 01$ ).

Nineteen patients were asymptomatic at diagnosis; none of these developed symptoms during a follow up of 2 to 21 years (mean (SD) 10 (7) years), however, four died suddenly. Seven of the 18 patients who presented with symptoms at diagnosis experienced either presyncopal or syncopal episodes or both; 12 had dyspnoea grade 2 and two had dyspnoea grade 3 of the New York Heart Association classification; and eight had exertional chest pain. Seven of the 18 patients died suddenly during a follow up of 1 to 9 years (mean (SD) 5 (3) years). The proportion of patients with chest pain and dyspnoea was similar (Table 1) in those who died suddenly and in the survivors but either presyncope or syncope, or both, were more common in patients who died suddenly $(\mathrm{P}<0 \cdot 01)$.

A clinical summary of those patients who died suddenly is presented in Table 2 . One of the 11 had a normal electrocardiogram at diagnosis; in two

Table 1 Clinical, electrocardiographic and haemodynamic findings in 19 survivors and in 11 patients who died suddenly

\begin{tabular}{|c|c|c|c|c|}
\hline & $\begin{array}{l}\text { Alive } \\
\text { No }\end{array}$ & $(\%)$ & $\begin{array}{l}\text { Sud } \\
\text { No }\end{array}$ & $\begin{array}{c}\text { den death } \\
(\%)\end{array}$ \\
\hline Chest pain & 3 & (16) & 3 & (27) \\
\hline Dyspnoea & 6 & (32) & 3 & (27) \\
\hline Syncope & 1 & (5) & 6 & (55) \\
\hline Left ventricular hypertrophy & 14 & (74) & 8 & (73) \\
\hline Right ventricular hypertrophy & 1 & (5) & 4 & (36) \\
\hline Left ventricular gradient & 10 & (59) & 5 & (56) \\
\hline Right ventricular gradient & 7 & (41) & 5 & (56) \\
\hline
\end{tabular}

17 of 19 survivors and 9 of 11 of those who died suddenly had left and right heart catheterisation. 
Hypertrophic cardiomyopathy: an important cause of sudden death 973
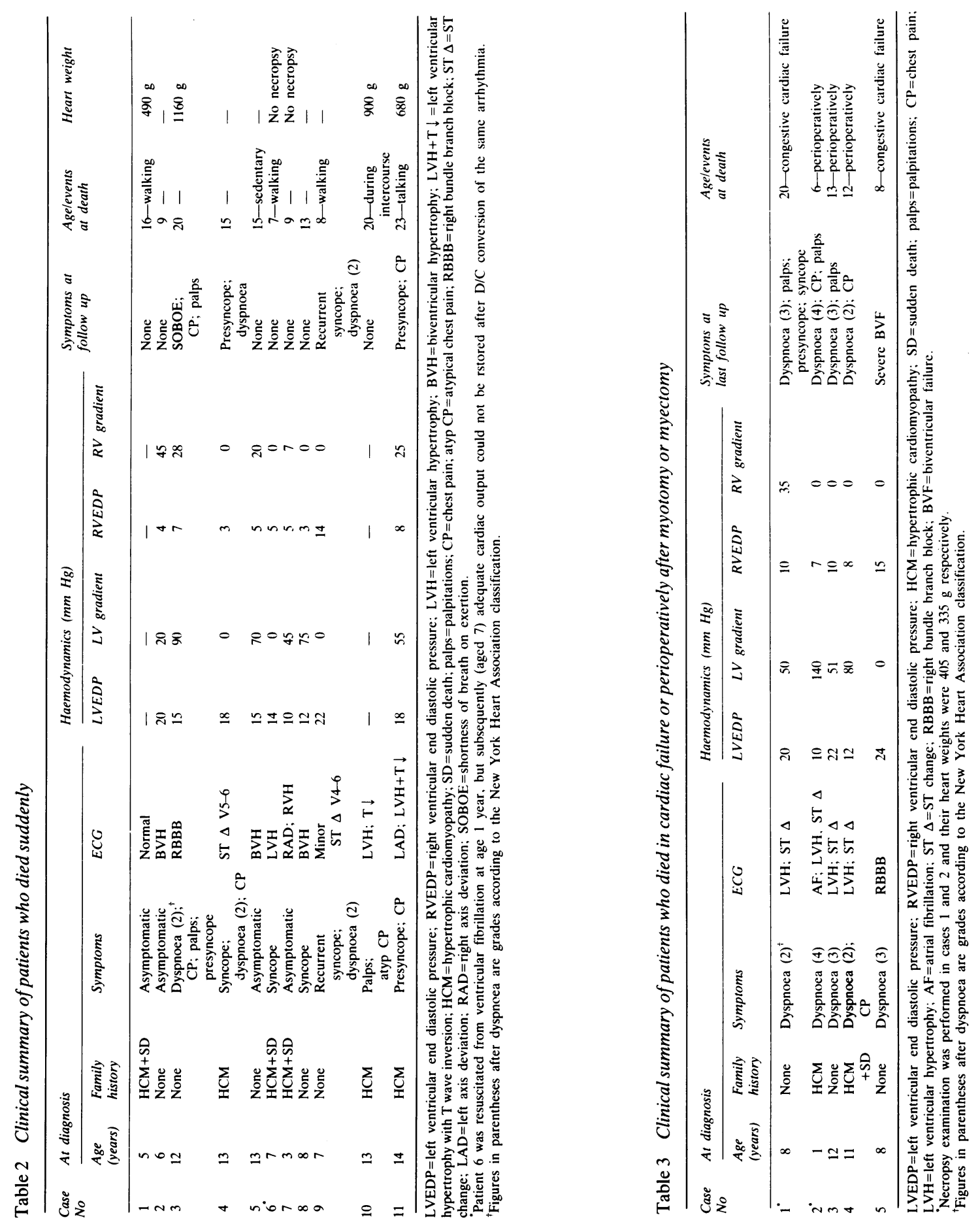

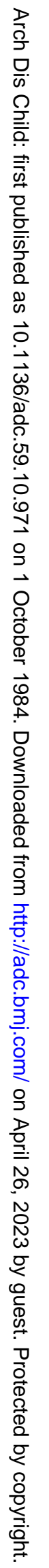


others the only abnormalities detected were minor repolarisation changes in leads V4-V6. Another had voltage criteria of right ventricular hypertrophy with a mean frontal plane voltage of $110^{\circ}$ at diagnosis. During follow up the axis shifted leftward $\left(+30^{\circ}\right)$ and there was progressive increase of voltage in lead AVL and SV1+RV5 and $70 \mathrm{mV}$ respectively. The remainder all had electrocardiographic evidence of left ventricular hypertrophy and three of these also fulfilled voltage criteria for right ventricular hypertrophy. Left ventricular hypertrophy was equally common $(73 \%)$ and the voltage in SV1+RV5 was similar among survivors (mean (SD) $44(25) \mathrm{mV}$ ) and those who died suddenly (45 (24) mV), however, only one of the survivors had electrocardiographic evidence of right ventricular hypertrophy: this finding was associated with sudden death $(\mathrm{P}<0.04)$. Left ventricular end diastolic pressure was not significantly different in the survivors (5 to $27 \mathrm{~mm} \mathrm{Hg}$, mean $14 \mathrm{~mm} \mathrm{Hg}$ ) and in those who died suddenly (10 to $22 \mathrm{~mm} \mathrm{Hg}$, mean $16 \mathrm{~mm} \mathrm{Hg}$ ) and the proportion of those with a left ventricular gradient at rest or after provocation was also similar (59 and $56 \%$ respectively). Right ventricular end diastolic pressure was 2 to $16 \mathrm{~mm} \mathrm{Hg}$ (mean $6 \mathrm{~mm}$ $\mathrm{Hg}$ ) in the survivors and 4 to $14 \mathrm{~mm} \mathrm{Hg}$ (mean $6 \mathrm{~mm}$ $\mathrm{Hg}$ ) in those who died suddenly. Though the proportion of patients with right ventricular gradients was greater in those who died suddenly (56 $v 41 \%$ ), this difference was not significant (Table 1). A similar proportion of survivors and those who died suddenly received propranolol (68 and $73 \%$ respectively).

Only three patients had progressive symptomatic limitation of exercise tolerance, however, these and the two patients with severe symptoms at diagnosis all died-two in cardiac failure and three perioperatively after myotomy or myectomy. The clinical features of these five patients are presented in Table 3. They had raised left and right ventricular end diastolic pressures but there was no other electrocardiographic or haemodynamic feature which distinguished them from the survivors.

\section{Discussion}

Clinical presentation with hypertrophic cardiomyopathy in childhood was associated with poor prognosis. Approximately half of the patients were dead nine years after diagnosis. This high mortality occurred despite selection criteria which excluded from the study those patients with affected family members who had died suddenly, a group recognised to be at particular risk. ${ }^{5-7}$ This study confirmed that children with hypertrophic cardiomyopathy who have severe or progressive symp- toms have a grim prognosis. ${ }^{3}$ More importantly it also showed that those patients with minimal or no functional limitation, who may have been considered to have a benign prognosis also had a poor prognosis with an annual mortality from sudden death of $4.3 \%$. Eleven of the 18 deaths were sudden, and of these only two had severe limitation of exercise tolerance.

Which clinical features identify the child with hypertrophic cardiomyopathy who is at particular risk of sudden death? A history of episodes of impaired consciousness and electrocardiographic evidence of right ventricular hypertrophy were the only clinical, electrocardiographic, or haemodynamic features which distinguished those patients who died suddenly from the survivors. In this study, though episodes of presyncope or syncope were specific $(86 \%)$, they were not sensitive as approximately half of the children who died suddenly had never experienced symptoms of impaired consciousness. Most patients in this study were evaluated before the availability of good quality echocardiographic recordings, and therefore electrocardiographic criteria were used to assess the presence and magnitude of left and right ventricular hypertrophy. Though electrocardiographic voltage criteria for right ventricular hypertrophy was associated with sudden death, the numbers involved were small and the assessment of right ventricular hypertrophy in the presence of left ventricular hypertrophy is difficult. Prospective echocardiographic confirmation of this finding is warranted. No difference was detected in the incidence or severity of electrocardiographic left ventricular hypertrophy in the survivors and in those who died suddenly. This is consistent with findings in previous studies in which there is a wide spectrum of myocardial hypertrophy both in adults and in children with hypertrophic cardiomyopathy who die suddenly. ${ }^{3} 613$ Hypertrophy is a non-specific marker for the underlying distribution of the disease. Though unproved it is logical to hypothesise that myocardial cellular disarray and myofibrillary disorganisation may predispose to arrhythmia and a myocardium which is electrically unstable. The findings by Maron $e t$ al of more noticeable myocardial cellular disarray in young patients compared with adults with hypertrophic cardiomyopathy who have died suddenly is consistent with this interpretation. ${ }^{14} 15$

The mechanism of sudden death in hypertrophic cardiomyopathy is unknown, but a propensity either to acute haemodynamic change or to ventricular arrhythmias, or both, is likely to be an important determinant. In adults with hypertrophic cardiomyopathy there is a $2.5 \%$ annual mortality from sudden death ${ }^{6}$ and approximately $25 \%$ of patients 
experience asymptomatic episodes of non-sustained ventricular tachycardia. ${ }^{17} 18$ The detection of ventricular tachycardia during ambulatory electrocardiographic monitoring is a sensitive clinical marker of those patients who are at particular risk. During treatment with conventional anti-arrhythmic agents the annual mortality from sudden death in these patients is approximately eight per cent. ${ }^{16} 18$ The incidence and importance of arrhythmias in children with hypertrophic cardiomyopathy is unknown. Information from small numbers of patients suggests that serious ventricular arrhythmias are less common than in adults and arrhythmias have not been detected in the small number of children who have had electrocardiographic monitoring performed before sudden death (unpublished data).

Can sudden death be prevented in these children? Beta blockers, calcium antagonists, and surgical myectomy are effective in the management of symptoms but their effect on prognosis has not been prospectively evaluated. ${ }^{6}$ The available evidence in adults, however, does not suggest that they will prevent sudden death. ${ }^{6}$ In the largest medical series, 28 of 32 patients who died suddenly were receiving propranolol $^{5}$ (mean dose $220 \mathrm{mg}$ daily). The results from the surgical centre with most experience show an annual mortality from sudden death of approximately two per cent after successful surgical myectomy and, furthermore, an eight per cent perioperative mortality. ${ }^{19}$ The only treatment which has shown promise in reducing sudden death is amiodarone.$^{20}$ In adults with hypertrophic cardiomyopathy and ventricular tachycardia a non-randomised study showed no mortality over three years in 21 patients on amiodarone in comparison with an eight per cent annual mortality in a matched population treated with conventional anti-arrhythmic agents. ${ }^{21}$ These results in adults, however, cannot be extrapolated to children. The cause of sudden death may be different in adults and children, and in addition amiodarone is associated with a high incidence of dose related, unwanted side effects. Thus, before a recommendation for treatment of children can be made, the antecedent mechanism of sudden death must be defined better to provide a rationale for treatment.

We thank Dr D M Krikler, Dr K Hallidie-Smith, Dr C M Oakley, and Professor J F Goodwin for allowing us to report patients under their care and to Diane England and Shaughan Dickie for technical and secretarial assistance.

\section{References}

1 Clark CE, Henry WL, Epstein SE. Familial prevalence and genetic transmission of idiopathic hypertrophic subaortic stenosis. N Engl J Med 1973;289:709-14.

${ }^{2}$ Fiddler GI, Tajik AJ, Weidman WH, McGoon DC, Ritter DG,
Giuliani ER. Idiopathic hypertrophic subaortic stenosis in the young. Am J Cardiol 1978;42:793-9.

3 Maron BJ, Henry WL, Clark CE, Redwood DR, Roberts WC, Epstein SE. Asymmetric septal hypertrophy in childhood. Circulation 1976;53:9-19.

${ }^{4}$ Schaffer MS, Freedom RM, Rowe RD. Hypertrophic cardiomyopathy presenting before two years of age in thirteen patients. Pediatr Cardiol 1983;4:113-9.

5 McKenna WJ, Deanfield J, Faruqui A, England D, Oakley CM, Goodwin JF. Prognosis in hypertrophic cardiomyopathy: role of age and clinical, electrocardiographic and hemodynamic features. Am J Cardiol 1981;47:532-8.

${ }^{6}$ McKenna WJ, Goodwin JF. The natural history of hypertrophic cardiomyopathy. Curr Probl Cardiol 1981;6:1-26.

${ }^{7}$ Maron BJ, Lipson LC, Roberts WC, Savage DD, Epstein SE. 'Malignant' hypertrophic cardiomyopathy: identification of a subgroup of families with unusually frequent premature death. Am J Cardiol 1978;41:1133-40.

${ }^{8}$ Goodwin JF. An appreciation of hypertrophic cardiomyopathy. Am J Med 1980;68:797-800.

9 Doi Y, McKenna WJ, Gehrke J, Oakley CM, Goodwin JF. M mode echocardiography in hypertrophic cardiomyopathy: diagnostic criteria and prediction of obstruction. Am J Cardiol 1980;45:6-14.

${ }^{10}$ Bethesda Conference on Optimal Electrocardiography. Task Force 1: standardization of terminology and interpretation. Am J Cardiol 1978:41:130-45.

1 Davignon A, Rautaharju P, Boisselle E, Soumis F, Megelas M, Choquette A. Normal ECG standards for infants and children. Pediatr Cardiol 1980;1:133-52.

12 Armitage P. Statistical methods in medical research. Oxford: Blackwell Scientific, 1977:411-4.

13 Maron BJ, Roberts WC, Edwards JE, McAllister HA, Jr, Foley DD, Epstein SE. Sudden death in patients with hypertrophic cardiomyopathy: characterization of 26 patients without functional Iimitation. Am J Cardiol 1978;41;803-10.

14 Maron BJ, Roberts WC. Quantitative analysis of cardiac muscle cell disorganization in the ventricular septum of patients with hypertrophic cardiomyopathy. Circulation 1979;59:689-706.

15 Maron BJ, Anan TK, Roberts WC. Quantitative analysis of the distribution of cardiac muscle cell disorganization in the left ventricular wall of patients with hypertrophic cardiomyopathy. Circulation 1981;63:882-94.

${ }^{16}$ Maron BJ, Savage DD, Wolfson JK, Epstein SE. Prognostic significance of 24 hour ambulatory electrocardiographic monitoring in patients with hypertrophic cardiomyopathy: a prospective study. Am J Cardiol 1981;48:252-7.

17 Savage DD, Seides SF, Maron BJ, Myers DJ, Epstein SE. Prevalence of arrhythmias during 24 hour electrocardiographic monitoring and exercise testing in patients with obstructive and nonobstructive hypertrophic cardiomyopathy. Circulation 1979;59:866-75.

${ }^{18}$ McKenna WJ, England D, Doi YL, Deanfield JE, Oakley CM, Goodwin JF. Arrhythmia in hypertrophic cardiomyopathy: I. Influence on prognosis. Br Heart $J$ 1981;46:168-72.

19 Maron BJ, Merrill WH, Freier PA, Kent KM, Epstein SE. Long-term clinical course and symptomatic status of patients after operation for hypertrophic subaortic stenosis. Circulation 1978;57:1205-13.

${ }^{20}$ McKenna WJ, Harris L, Rowland E, et al. Amiodarone for long term management in hypertrophic cardiomyopathy. Am J Cardiol 1984;54:802-10.

${ }^{21}$ McKenna WJ, Oakley CM, Goodwin JF. The influence of amiodarone on survival in hypertrophic cardiomyopathy (abstract). Circulation 1983;68:111-61.

Correspondence to Dr W J McKenna, Hammersmith Hospital, Du Cane Road, London W12 0HS.

Received 27 June 1984 